Economic and Environmental Geology

Short Note

\title{
New Occurrence of Haengmae Formation in Taebaeksan Basin
}

\author{
Yungoo Song ${ }^{1}$, Chaewon Park ${ }^{1}$, Namsoo Kim ${ }^{1}$, Sung-Ja Choi ${ }^{2 *}$, Ueechan Chwae ${ }^{3}$, Sanghoon Kwon ${ }^{1}$, \\ Yirang Jang ${ }^{4}$ \\ ${ }^{1}$ Department of Earth System Sciences, Yonsei University, Seoul, 03722, Korea \\ ${ }^{2}$ Korea Institute of Geoscience and Mineral Resources (KIGAM), Daejeon 34132, Korea \\ ${ }^{3}$ S/C Contemporary, Daejeon, 34139, Korea \\ ${ }^{4}$ Faculty of Earth System and Environmental Sciences, Chonnam National University, Gwangju, 61186, Korea
}

*Corresponding author : sjchoi@kigam.re.kr

\section{ARTICLE INFORMATION}

Manuscript received 24 May 2021

Received in revised form 18 June 2021

Manuscript accepted 19 June 2021

Available online 28 June 2021

DOI : http://dx.doi.org/10.9719/EEG.2021.54.3.365

\author{
Research Highlights \\ - Pebble-bearing clastic carbonate rocks were newly recognized in \\ the northeastern part of the Taebaek Basin \\ - Haengmae Formation extends from Mitan through the western \\ Jeongseon to Gangneung
}

\begin{abstract}
Pebble-bearing clastic carbonate rock which has been found in and around the Jeongseon and Okgye through the field survey was studied in petrological and mineralogical characteristics. We define the clastic carbonate rocks as 'Dolomite-pebble bearing fine sandsized dolostone, or grainstone', which are characterized by the existence of dolomite single grains and Mg-phengite, and by the subsequent formation of secondary calcite cements. These attributes correspond well with those of the typical Haengmae Formation from Haengmae-dong, Mitan-myeon, Jeongseon-gun, thus the carbonate rocks in the Jeongseon and Okgye areas must belong to the Haengmae Formation. The result suggests that the Haengmae Formation is an independent unit among the Paleozoic lithostratigraphic units in Taebaek basin and lies in the upper part of Jeongseon and Sukbyungsan Formations under the Hongjeom Formation of Pyeongan Supergroup.
\end{abstract}

Keywords : Haengmae Formation, Hoedongri Formation, Jeongseon-Okgye, Dolomite, phengite

Citation: Song, Y., Park, C., Kim, N., Choi, S.-J., Chwae, U., Kwon, S., Jang, Y. (2021) New Occurrence of Haengmae Formation in Taebaeksan Basin. Korea Economic and Environmental Geology, v.54, p.365-372, doi:10.9719/EEG2021.54.3.365.

This is an Open Access article distributed under the terms of the Creative Commons Attribution Non-Commercial License (http://creativecommons.org/ licenses/by-nc/3.0) which permits unrestricted non-commercial use, distribution, and reproduction in any medium, provided original work is properly cited. pISSN 1225-7281; eISSN 2288-7962/C2021 The KSEEG. Printed by Hanrimwon Publishing Company. All rights reserved. 


\title{
단보
}

\section{태백산분지 내 새로운 행매층 분포 확인}

\author{
송윤구 $^{1} \cdot$ 박채원 $^{1} \cdot$ 김남수 $^{1} \cdot$ 최성자 $^{2 *} \cdot$ 최위찬 $^{3} \cdot$ 권상훈 $^{1} \cdot$ 장이랑 $^{4}$ \\ ${ }^{1}$ 연세대학교 \\ 2한국지질자원연구원 \\ ${ }^{3}$ 에스씨 컨템포라리 \\ ${ }^{4}$ 전남대학교
}

*책임저자 : sjchoi@kigam.re.kr

\section{요 약}

행매층은 정선석회암과 회동리층 사이에 위치하며 회동리층의 존재 및 지질시대를 결정하게 하는 중요한 역할을 하는 지층이 다. 행매층의 분포조사를 통해 정선 및 옥계 일원에서 쇄설성 탄산염암이 확인되었으며 이들에 대한 암석학적 및 광물학적 특 성을 규명하였다. 쇄설성 탄산염암의 암상 특성은 함돌로마이트역-미사질 백운암, 혹은 입자암(Dolomite-pebble bearing fine sand-sized dolostone, or grainstone)으로 정의할 수 있다. 광물조성 및 미세구조적 특징으로는 단결정 돌로마이트와 Mg-펜자이 트의 존재, 그리고 입자 사이를 충진하는 교질물질로 나타나는 방해석의 생성이다. 이 같은 특성은 정선군 미탄면 행매동 일원 의 전형적인 행매층의 특성과 일치하고 있어, 정선과 옥계 일원의 쇄설성 탄산염암이 행매층임을 지시한다. 본 연구결과는 태 백산분지 내에서 행매층은 독립 암층서단위일 뿐만 아니라 평안누층군 홍점층 직하부의 조선누층군인 정선석회암과 석병산석 회암 상부에 분포하고 있음을 제시해 준다.

주요어 : 행매층, 회동리층, 정선-옥계, 돌로마이트, 펜자이트

\section{1. 서 언}

행매층은 Hisakoshi (1943)에 의해 명명된 행막층이 Son and Cheong (1976)에 의해 재명명된 지층으로, 실루리아 기로 정의된 회동리층 (Cheong et al., 1979) 직하부에 위 치한 쇄설성 탄산염암층이다. 이 지층은 정선석회암과는 부정합 관계를 보이며, 상부의 회동리층과 하부의 정선 석회암과 구분할 수 있는 중요한 층서단위이다. 최근 회 동리층과 행매층에 대한 논란이 있었으나, $\mathrm{Kim}$ et al. (2020)은 Cheong et al.(1979)과 Lee(1980, 1982, 1983)가 제시한 정선 일대의 회동리층과 행매층 분포지를 중심으 로 정밀 지질조사를 통해 회동리층과 행매층의 지질도를 재작성하여 행매층이 독립 “층” 임을 분명히 하였을 뿐 만 아니라, 행매층 형성시기가 상부 오르도비스기 Katian 이후 (Jang, 2017) 임을 제시하였다.

Lee(1987)은 정선-평창지역, 백운산 향사대의 영월-상 동, 태백, 장성지역 등지를 조사하여 기존에 알려져 있던 평창군 미탄면 평안리, 미탄면 고길리, 평창면 대화리, 정 선군 정선읍 회동리 뿐만 아니라 회동리 북동지역인 정 선읍 북평면 여량리까지 회동리층이 연장 분포됨을 확인 하였다. 그러나 그는 회동리층에 대한 동쪽 연장성만을 기재하고 있을 뿐, 행매층의 분포에 대해서는 언급하지
않았다. 한편, 행매층이 하부고생대지층들에 대하여 층서 적 의미가 큰 지층 단위일 수 있음에도, 태백산분지 내 에서 행매층의 분포한계를 규명한 적은 없다. 본 연구의 연구자들은 행매층 분포의 중요성을 인지하고, Kim et al.(2020)의 후속연구로 행매층에 대한 정밀 지질도 작성 을 진행 중이다. 이 연구에서는 기 발간된 $1: 50,000$ 지질 도 상에 표기된 정선 일대의 정선석회암과 옥계지역의 석병산석회암을 대상으로 행매층 분포에 대한 지질조사 를 실시하여 정선과 옥계지역에서 쇄설성 탄산염암층의 존재를 확인하였다. 본 연구에서는 암석학적 및 광물학 적 특성 연구를 통해 새롭게 확인된 쇄설성 탄산염암이 평창군 미탄면 평안리 일대에 노출된 행매층과 동일한 암상임을 규명하고자 하였으며, 이를 통해 행매층이 정 선읍 회동리 동쪽으로 연장될 수 있음을 제시하고자 한다.

\section{2. 대상지역 지질개요}

본 연구의 조사 대상지역은 정선군 서부, 북부지역 및 강릉시 옥계면 지역으로, 한국지질자원연구원 $1: 50,000$ 지질도 기준으로 정선군 일대에서는 정선석회암을, 그리 고 강릉시 옥계면 일대에서는 석병산석회암을 대상으로 지질조사를 수행하였다(Fig. 1). 


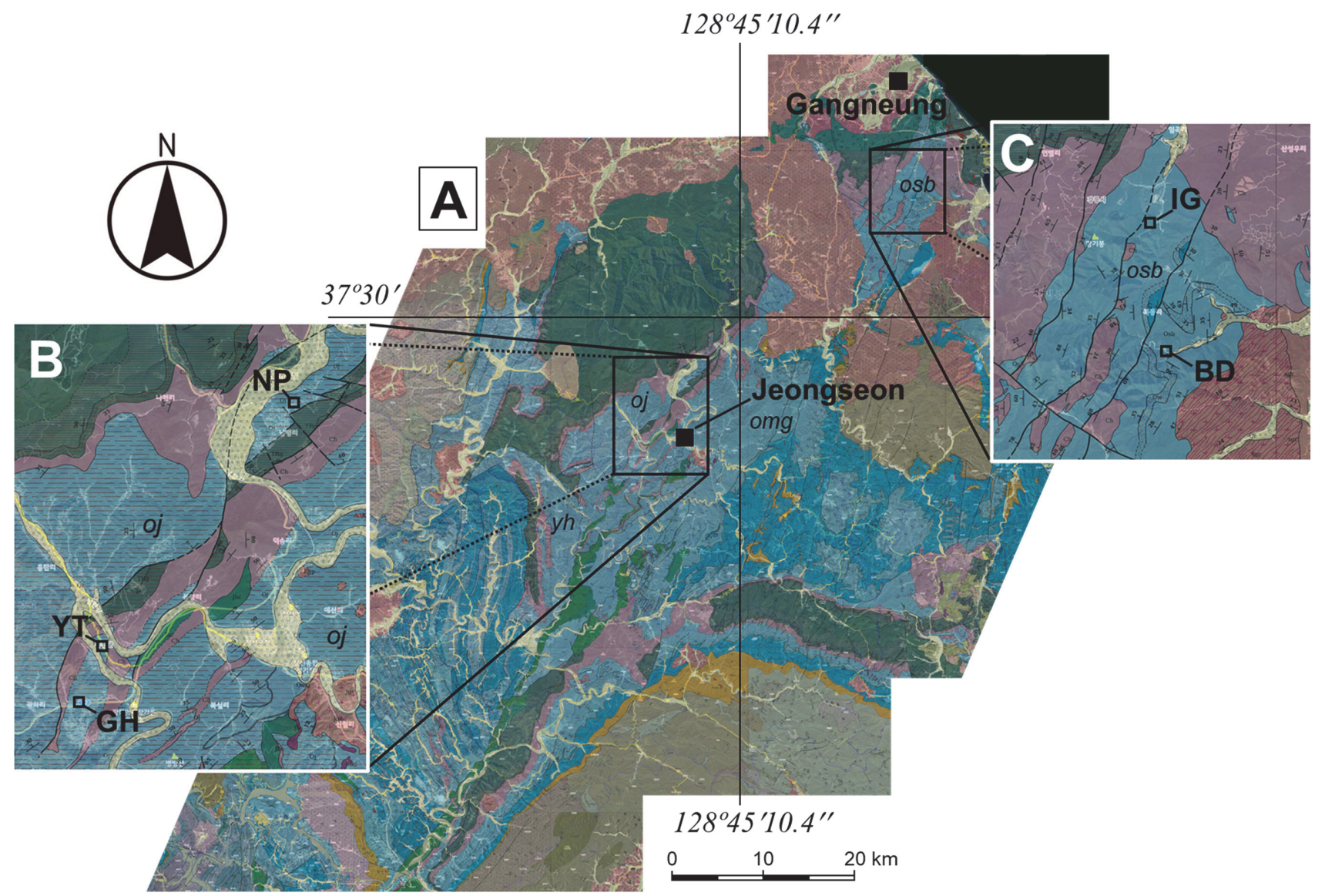

Fig. 1. Geological map of northeastern part of the Korean Peninsula (A) with exaggerated maps (B and C), showing sampling locations in this study (captured from https://mgeo.kigam.re.kr/map/main.do?process=geology_50k). Abbreviations: oj; Jeongseon Limestone, yh; Youngheung Formation, omg; Magdong Formation, and osb; Seokbyungsan Formation. Sampling locations: NP; Nampyeong-ri, GH; Gwangha-ri, YT; Yongtan-ri, IG; Imgok-ri, and BD; Bukdong-ri.

Geological Investigation Corps of Taebaeksan Region (GICT) and Geological Society of Korea(GSK)(1962)는 정 선석회암이 막동석회암 위에 정합으로 놓이는 층서를 설 정한 바 있는 반면, Son and Cheong(1976)는 Hisakoshi (1943)의 행매층을 인정하고 이 행매층이 조선누층군을 사교 부정합으로 덮으며, 조선누층군의 정선석회암과 막 동석회암은 부정합 관계로 보았다. Cheong et al.(1979) 는 정선 서부지역의 석회암(소위 정선석회암 최상부)에 서 산출된 코노돈트 화석군이 실루리아기임을 밝히고 이 지층을 새로운 암층서 단위로 설정하여 회동리층으로 명 명하였다. 그리고 회동리층의 하위에 발달하고 있는 Hisakoshi(1943)의 행매층을 인정하고 행매층 하위의 하 부석회암층과 정선 동부지역에서 Hisakoshi(1943)가 정의 한 정선석회암, GICT and GSK(1962)의 정선석회암을 모 두 통합하여 정선석회암으로 한 바 있다. 상기의 행매층 은 평창군 평창읍 남병산, 평창읍 애화리, 미탄면 평안리, 정선군 정선읍 회동리, 정선군 정선읍 여량지역까지 연
장된다(Lee, 1987). 정선석회암의 북동 연장부에는 임계 화강암이 출현하고 있다. 화강암 동쪽에 위치한 강릉, 옥 계, 석병산 지역에는 하부고생대 석회암층이 발달하고 있 으며, 이 지역의 상부 지층은 석병산석회암으로 평안누 층군과 부정합으로 직접하고 있다(Fig. 1). 이곳의 석병 산석회암을 GICT and GSK(1962)은 막동석회암에 대비 하였다.

\section{3. 정선 - 옥계 일대 쇄설성 탄산염암 특성}

\section{1. 분포와 암상}

소위 매화구조선-옥동단층(Kobayashi, 1953)의 북동쪽 연장인 고기 대단층(choi et al., 1992)을 따라, 정선군 정 선읍 광하리 $(\mathrm{GH})$, 용탄리 $(\mathrm{YT})$, 정선군 북평면 남평리 $(\mathrm{NP})$, 강릉시 강동면 임곡리(IG) 및 옥계면 북동리(BD) 까지 5 개 지점에서 쇄설성 탄산염암의 분포를 확인하였다(Fig. 1). 모든 지점은 평안누층군의 홍점층 직하부에 놓이는 조선 

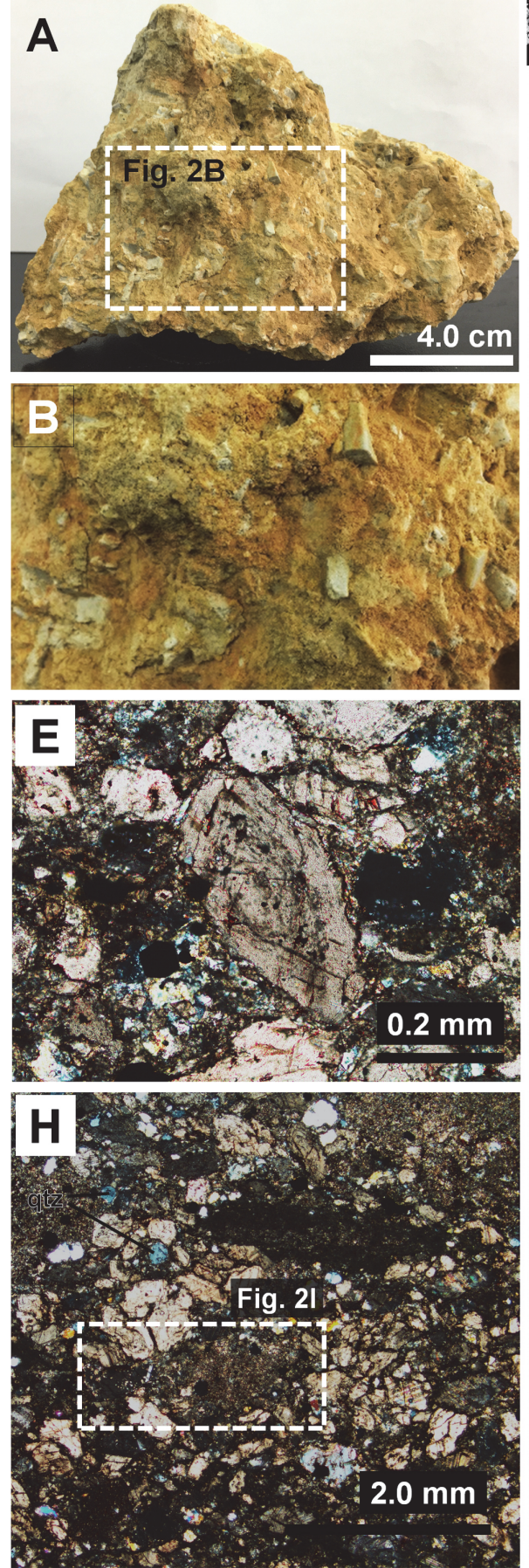
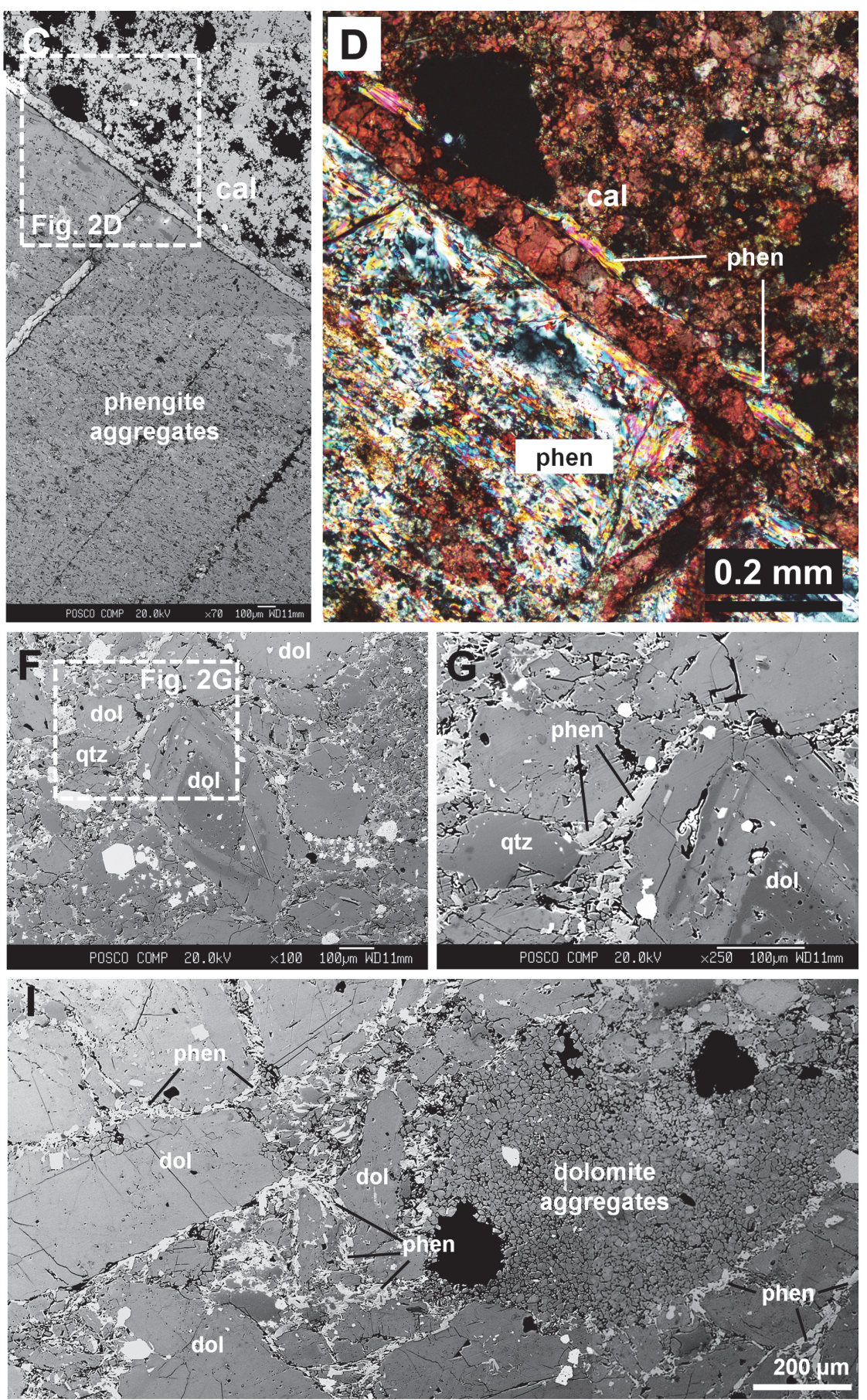

Fig. 2. Massive yellowish pebble-bearing carbonate rock from the Nampyeong-ri (NP) site (A), which is characterized by the typical phengite aggregates scattered in the rock with white-colored and several centimeters in length (B), and its back-scattered electron (BSE) microscopic image (C) and polarized microscopic image under crossed polarized light (XPL) mode after alizarin red S staining (D), showing that the aggregate is composed of polycrystalline phengite with less than $100 \mu \mathrm{m}$ in size and is surrounded by calcitefillings (stained as red). XPL (E and H) and BSE (F, G, and I) images of a pebble-bearing carbonate rock found in the Gwangha-ri $(\mathrm{GH})$ site, showing a typical texture composed of sub-rounded single crystalline dolomite and quartz grains (E, F, and G), and a finegrained dolomite aggregate (H and I) with phengite in matrix. Abbreviations: dol; dolomite, cal; calcite, phen; phengite, and qtz; quartz.

누층군 석회암층(정선석회암 및 석병산석회암) 내에 위 치하며, 이는 기존에 보고된 행매층의 층서분포특성(Cheong et al., 1979; Lee, 1980, 1982, 1983, 1987; Jang, 2017, Kim et al., 2020)과 동일하다. 
본 연구의 지질조사를 통해 나타난 쇄설성 탄산염암의 암상 특성은 다음과 같다. 1) 거력(Boulder)의 석영질 아 레나이트(arenite)를 포함하고 있는 황갈색 함역 백운암, 2) 수 $\mathrm{cm}$ 크기의 돌로마이트 역을 함유한 백운암, 3) 돌 로마이트 역과 석영 집합체(aggregate) 형태가 섞여서 나 타나는 백운암 등이다. 정선군 남평리 노두(NP)에서는 수 $\mathrm{cm}$ 크기의 펜자이트(phengite)가 백색 사각주 형태로 혼 재 되어 나타나기도 한다(Fig. $2 \mathrm{~A}$ and $\mathrm{B}$ ). 일부 노두 표 면에 침식으로 인하여 형성된 곰보형의 요철구조는 돌로 마이트 역이 물리 화학적 침식으로 인해 빠져나간 조직 으로 판단된다. 야외에서 염산으로 반응하는 부분은 입 자 사이에 분포되어 있는 방해석 교결물질(cement)이 대 부분이다. 흔히 이전 연구에서 행매층 암상 표현에 많이 쓰였던 ‘황갈색 함역 석회암’ 보다 ‘함역 돌로마이트'가 훨씬 빈번히 나타남은 주목할 만하다.

이 지역에서 행매층은 대체로 황갈색을 띠고 있는 괴
상의 퇴적상을 보이며, 드물게 엽층리를 보이는 수십 $\mathrm{cm}$ 두께의 층과 $5-10 \mathrm{~cm}$ 두께의 회색 석회암층이 괴상의 함 역 돌로마이트와 교호한다. 이와 같은 함역 쇄설성 탄산 염암의 암상 특성은 Kim et al.(2020)에 의해 기재된 행 매층의 특성과 동일한 함돌로마이트역-미사질 백운암, 혹 은 입자암(Dolomite-pebble bearing fine sand-sized dolostone, or grainstone)으로 정의할 수 있다.

\section{2. 광물학적 특성}

본 연구조사에서 새로 확인된 쇄설성 탄산염암의 제작 된 박편에 대한 편광현미경 및 주사전자현미경(SEM) 관 찰, 광물의 전자현미분석(EPMA)과 광물조성 확인을 위 한 X-선 회절분석(XRD)을 실시하여 광물학적 특성을 확 인하였다.

쇄설성 탄산염암의 광물학적 특성을 요약하면 다음과 같다. 1) 돌로마이트가 주구성광물로, $0.1 \sim 1.0 \mathrm{~mm}$ 크기
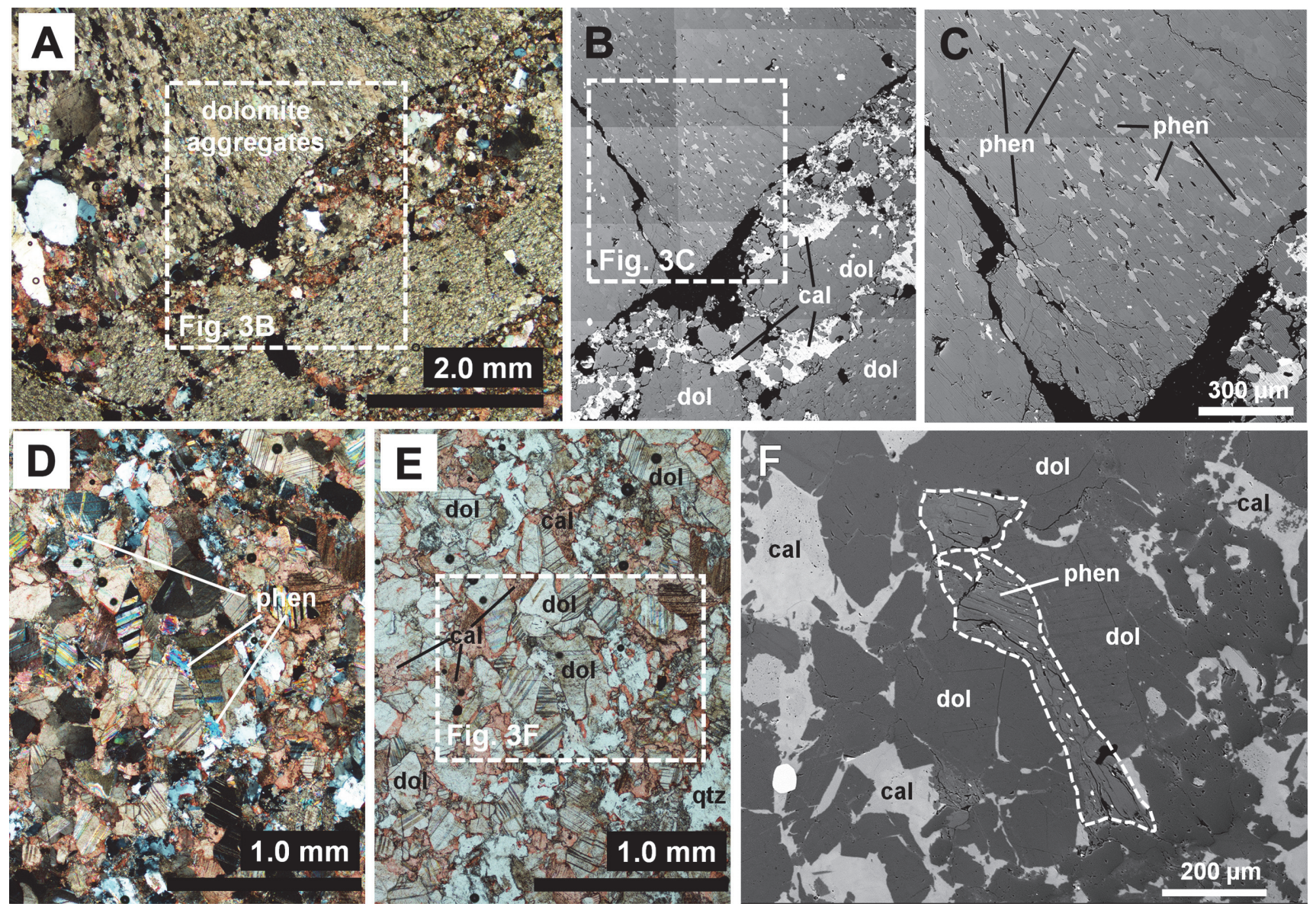

Fig. 3. Polarized microscopic images under crossed polarized light (XPL)(A and D) and plane polarized light (PPL)(E) modes after alizarin red S staining, and BSE images (B, C, and F) of a carbonate rocks from the Imgok-ri (IG) and Bukdong-ri (BD) sites. The carbonate rocks are mainly composed of dolomite aggregate (A), single crystalline dolomite and quartz (D and E). Phengite occurs in both of dolomite aggregate $(\mathrm{B}$ and $\mathrm{C})$ and matrix $(\mathrm{F})$, and calcite is existed in matrix as filling materials (B and F). Abbreviations: dol; dolomite, cal; calcite, phen; phengite, and qtz; quartz. 
의 주로 반자형 내지 타형의 단결정으로 나타난다(Fig. $2 \mathrm{E} \mathrm{I}$, Fig. 3D F, and Fig. 4). 2) 미립질(10 20 $\mu \mathrm{m})$ 의 돌로마 이트 집합체가 수 $\mathrm{mm}$ 에서 수 $\mathrm{cm}$ 까지 다양한 크기 및 원 마도를 보이며 나타난다(Fig. $2 \mathrm{H}$ and I, and Fig. 3A C). 3) 펜자이트가 세립질 $(<0.1 \mathrm{~mm})$ 집합체(Fig. $2 \mathrm{C}$ and D), 또는 광물입자와 역 사이를 충진하는 형태(Fig. $2 \mathrm{E} \sim \mathrm{I}$ and Fig. 3)로 모든 시료에서 관찰된다(Fig. 4). 4) 방해석은 역, 돌로마이트 등의 입자 사이를 이차적으로 충진하는 미립질의 교질물질로 나타나며(Fig. 2 and 3), 일부 시료 (NP 지점) 기질에서는 그 함량이 매우 높게 나타나기도 한다(Fig. 2C and D, and Fig. 4B). 5) 석영은 $0.1 \mathrm{~mm}$ 내 외의 크기로 중간 정도 원마도를 보이는 단결정으로 소 량 나타난다.

모든 대상 시료에서 관찰되는 펜자이트에 대한 EPMA 주원소 정량분석 결과 및 산소 22 기준으로 계산된 결정 구조식 결과를 Table 1에 제시하였다. 펜자이트 구조식

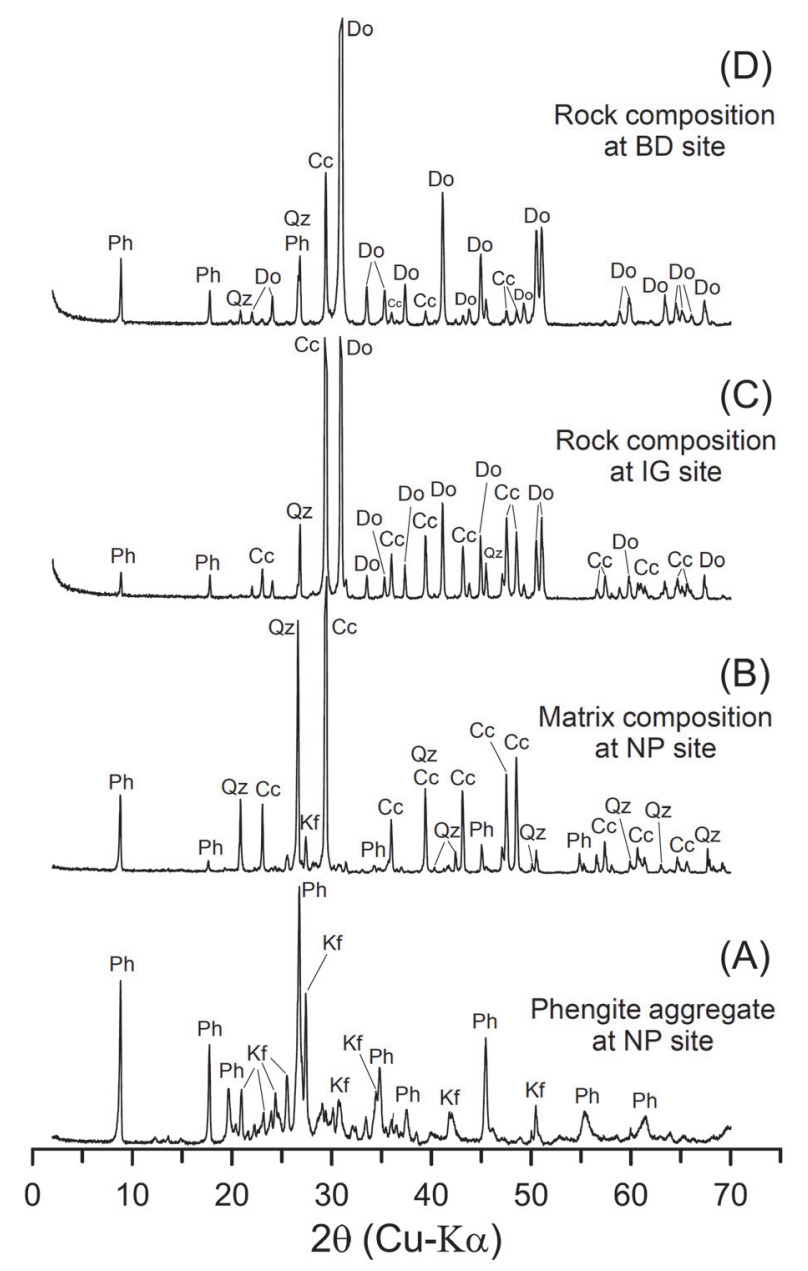

Fig. 4. Bulk X-ray diffraction patterns of some carbonate rocks collected from the study area. Abbreviations: Do; dolomite, Qz; quartz, Cc; calcite, $\mathrm{Ph}$; phengite, and Kf; K-feldspar.
계산 결과, 산소 22 기준으로 팔면체자리 4 개이던 $\mathrm{Al}^{3+}$ 을 미원자 수 중 $\mathrm{Mg}^{2+}$ 원자가 $0.55 \sim 1.25$ 개까지 치환하며, 정전기적 균형을 위해 사면체자리 8개 중 6 개 이던 $\mathrm{Si}^{4+}$ 의 치환도가 6.41 7.14 까지 증가하는 전형적인 백운모알루미노셀라도니트(muscovite-aluminoceladonite) 사이의 고용체광물인 $\mathrm{Mg}$-펜자이트임을 알 수 있다(Table 1). 이 는 Park et al.(2020)에 의해 제시된 행매층 펜자이트와 화학조성에서 거의 동일하다. 펜자이트 집합체에 대한 X선 회절분석 결과, 이팔면체 운모의 (060) 회절선(20 61.5', $1.50 \AA ̊)$ 이 나타나고 있어 화학조성 특성과 함께 이 광물 이 이팔면체 운모 광물군에 속하는 펜자이트임을 지시한다. 광물학적 특성에서 대상 탄산염암은 대부분 시료에서 상대적으로 낮은 펜자이트 및 석영 함량을 갖는 차이를 보이기도 하지만, 매우 독특한 단결정 돌로마이트와 펜 자이트 광물이 나타난다는 점에서 행매층의 광물학적 특 성(Kim et al., 2020; Park et al., 2020)과 매우 유사하다. 미세조직 특징에서도 나타나는 쇄설성 특성을 보이는 돌 로마이트 역과 석영입자, 원지성(in-situ) 생성 특성을 보 이는 높은 마그네슘 $(\mathrm{Mg})$ 함량을 갖는 단결정 돌로마이 트와 펜자이트, 그리고 이 후에 공극을 이차적으로 충진 하며 교질물질로 나타나는 방해석의 선후관계 등의 특성 도 Park et al.(2020)의 행매층 암석과 동일하다.

\section{4. 토의 및 결론}

본 연구에서 정선군 서부, 북부지역 및 강릉시 옥계면 지역에서 확인한 쇄설성 탄산염암은 암석학적으로는 함 돌로마이트역-미사질 백운암, 혹은 입자암(Dolomite-pebble bearing fine sand-sized dolostone, or grainstone)으로 분 류될 수 있으며, 광물학적으로는 높은 $\mathrm{Mg}$ 함량을 갖는 단결정 돌로마이트와 펜자이트의 존재로 요약할 수 있다. 이러한 특성은 Kim et al.(2020)과 Park et al.(2020)이 제 시한 행매층의 특성과 일치하며, 따라서 이들 암석이 행 매층임을 지시한다.

이번 연구에서는 기존에 보고된 행매층 분포지역 이외 에서도 행매층이 존재함을 규명하였다. 평안누층군 홍점 층 직하부에 놓이는 조선누층군의 정선석회암과 석병산 석회암 상부에서 쇄설성 탄산염암의 존재를 확인하고 이 들이 암석학적 및 광물학적 특성상 기존의 행매층과 동 일함을 밝힘에 따라 태백산분지 내 하부고생대 층서를 재정립할 필요성이 있음을 제시하였다. 행매층에 대한 정 밀지질도 작성을 위해 정선, 영월, 석항 지역에서도 트러 스트 단층에 의해 반복적으로 나타나는 홍점층 하부의 석회암층에 대한 추가조사가 필요하다. 또한 이번 연구 에서는 행매층이 독립된 암층서임을 다시 한번 확인하였 
Table 1. Representative electron probe micro analyzer (EPMA) results and the structural formulae of the phengites from the Jeongseon and Okgye area

\begin{tabular}{|c|c|c|c|c|c|c|c|c|}
\hline & \multicolumn{2}{|c|}{ NP } & \multicolumn{2}{|c|}{ GH } & \multicolumn{2}{|c|}{ IG } & \multicolumn{2}{|c|}{$\mathrm{BD}$} \\
\hline & Min. & Max. & Min. & Max. & Min. & Max. & Min. & Max. \\
\hline $\mathrm{SiO}_{2}$ & 51.14 & 51.24 & 50.36 & 50.36 & 46.02 & 50.12 & 49.16 & 50.88 \\
\hline $\mathrm{TiO}_{2}$ & 0.08 & 0.03 & 0.30 & 0.30 & 0.83 & 0.36 & 0.08 & 0.12 \\
\hline $\mathrm{Al}_{2} \mathrm{O}_{3}$ & 24.26 & 22.20 & 25.89 & 25.89 & 30.13 & 25.34 & 28.81 & 25.77 \\
\hline $\mathrm{FeO}^{*}$ & 0.08 & 0.09 & 0.32 & 0.32 & 0.04 & 0.04 & 0.07 & 0.18 \\
\hline $\mathrm{MnO}$ & 0.00 & 0.00 & 0.00 & 0.00 & 0.00 & 0.04 & 0.00 & 0.00 \\
\hline $\mathrm{MgO}$ & 4.59 & 6.00 & 4.06 & 4.06 & 2.75 & 4.21 & 2.69 & 3.90 \\
\hline $\mathrm{CaO}$ & 0.06 & 0.08 & 0.31 & 0.31 & 0.10 & 0.15 & 0.13 & 0.14 \\
\hline $\mathrm{Na}_{2} \mathrm{O}$ & 0.16 & 0.07 & 0.10 & 0.10 & 0.10 & 0.14 & 0.03 & 0.05 \\
\hline $\mathrm{K}_{2} \mathrm{O}$ & 10.78 & 10.89 & 10.69 & 10.69 & 10.91 & 10.82 & 11.07 & 10.83 \\
\hline sum & 91.14 & 90.59 & 92.04 & 92.04 & 90.86 & 91.23 & 92.03 & 91.88 \\
\hline $\mathrm{Si}$ & 7.0633 & 7.1396 & 6.9021 & 6.9021 & 6.4145 & 6.9295 & 6.7312 & 6.9702 \\
\hline $\mathrm{Al}(\mathrm{T})$ & 0.9367 & 0.8604 & 1.0979 & 1.0979 & 1.5855 & 1.0705 & 1.2688 & 1.0298 \\
\hline Sum(T) & 8.0000 & 8.0000 & 8.0000 & 8.0000 & 8.0000 & 8.0000 & 8.0000 & 8.0000 \\
\hline $\mathrm{Al}(\mathrm{O})$ & 3.0123 & 2.7857 & 3.0837 & 3.0837 & 3.3637 & 3.0591 & 3.3810 & 3.1319 \\
\hline $\mathrm{Ti}$ & 0.0080 & 0.0030 & 0.0311 & 0.0311 & 0.0871 & 0.0369 & 0.0083 & 0.0125 \\
\hline $\mathrm{Fe}(2+)$ & 0.0088 & 0.0101 & 0.0369 & 0.0369 & 0.0044 & 0.0047 & 0.0078 & 0.0207 \\
\hline Mn & 0.0000 & 0.0004 & 0.0003 & 0.0003 & 0.0000 & 0.0044 & 0.0000 & 0.0001 \\
\hline $\mathrm{Mg}$ & 0.9445 & 1.2466 & 0.8303 & 0.8303 & 0.5708 & 0.8673 & 0.5487 & 0.7969 \\
\hline $\operatorname{Sum}(\mathrm{O})$ & 3.9735 & 4.0458 & 3.9824 & 3.9824 & 4.0261 & 3.9725 & 3.9459 & 3.9621 \\
\hline $\mathrm{Ca}$ & 0.0090 & 0.0115 & 0.0458 & 0.0458 & 0.0142 & 0.0224 & 0.0194 & 0.0211 \\
\hline $\mathrm{Na}$ & 0.0439 & 0.0192 & 0.0271 & 0.0271 & 0.0273 & 0.0386 & 0.0066 & 0.0141 \\
\hline K & 1.8993 & 1.9349 & 1.8685 & 1.8685 & 1.9396 & 1.9091 & 1.9341 & 1.8923 \\
\hline Sum & 1.9523 & 1.9656 & 1.9414 & 1.9414 & 1.9811 & 1.9700 & 1.9601 & 1.9275 \\
\hline
\end{tabular}

The structural formulae were calculated on basis of 22 oxygens.

*Total $\mathrm{Fe}$ is calculated as ferrous.

으며, 이를 통해 회동리층의 분포, 형성시기를 명확히 할 수 있을 것으로 판단된다. 본 연구 결과를 기초로 행매 층의 분포에 대한 정밀 지질도가 작성된다면, 행매층의 퇴적환경, 행매층 지질시대 결정, 행매층과 정선석회암의 관계, 정선석회암과 막동석회암, 영흥층, 고성석회암 및 태백산분지 동측의 석병산석회암 등과의 관계 및 지질시 대 규명, 회동리층과 실루리아기 퇴적층 연장 발달 유무 확인 등이 가능할 것으로 보이며 이는 하부 고생대 층서 규명에 대한 중요한 기초자료가 될 것이다.

\section{사 사}

본 연구는 한국지질자원연구원의 과학기술정보통신부 주요사업 “판내부 활성지구조 특성연구 및 단층 분절모 델개발"(과제코드 GP2020-014/21-3116)의 일환으로 수행
되었습니다. 그리고 이 논문을 읽고 비평과 교정을 해주 신 익명의 심사위원님들에게 감사드립니다.

\section{References}

Cheong, C.H., Lee, H.Y., Kog, I.S. and Lee, J.D. (1979) A study on stratigraphy and sedimentological environments of the Lower Paleozoic Sequences in South Korea (chiefly in Jeongseon area). Jour. Nat. Acad. Sci. T.O.K. Nat. Sci. Ser., v.18, p.125-159.

Choi, S.-J., Um, S.H., Chun, H.Y., Lee, H.Y., Kim, B.C. and Kwon, Y.I. (1992) A possible existence of the Paleo-Great fault based on the Difference of fossil and shortening of the Upper Paleozic strata. Jour. Geo. Soc. Korea, v.28, p.239-249.

Geological Investigation Corps of Taebaeksan Region (GICT) and Geological Society of Korea (GSK) (1962) Geological Atlas of Taebaegsan Region. 17 tabs.

Hisakoshi, S. (1943) Geology of Seizen District, Kogendo, Tyosen. 
Jour. Soc. Japan, v.50, p.269-277.

Jang, Y. (2017) Structural style of the Phanerozoic polyphase orogenic belt in the western Taebaeksan Zone, Okcheon Belt, Korea: Insights from multidisciplinary analyses. Ph.D. Thesis, Yonsei University, 220p.

Lee, B.S. (2020) Conodonts from the 'Lower Limestone' and Haengmae Formation in western Jeongseon, Korea and their implication for lithostratigraphic correlation. Geosciences Journal, v.24, p.113-120. doi: 10.1007/s12303-019-0034-7.

Lee H.-Y. (1980) Discovery of Silurian Conodont fauna from South Korea. Jour. Geol. Soc. Korea, v.16, p.114-123.

Lee, H.-Y. (1982) Conodonts from the Hoedongri Formation (Silurian), Western Jeongseon area, Kangweon-do, South Korea. Jour. Nat. Acad. Sci., KINX 1982030966, v.21, p.43-132.

Lee, H.-Y. (1983) Conodont Biostratigraphy of the Hoedongri Formation (Silurian) in the Western Jeongseon Area, Kangweondo, South Korea. Jour. Nat. Sci. Res. Ins., v.12, p.7799.

Lee, H.-Y. (1987) A confirmation of the Middle Paleozoic sediments in the Taebaegsan region (Jeongseon, Pyeongchang, Yeongweol and Samcheog) in South Korea. Yonsei University,
TRKO200200010416.

Kim, N., Choi, S.-J., Song, Y., Park, C., Chwae, U. and Yi, K. (2020) Distribution and Stratigraphical Significance of the Haengmae Formation in Pyeongchang and Jeongseon areas, South Korea. Econ. Environ. Geol., v.53, p.383-395. doi: 10.9719/EEG.2020.53.4.383.

Kobayashi, T. (1953) Geology of South Korea. Univ. Tokyo Fac. Sci. J. Sect. 2, v.8, p.145-293.

Kobayashi, T. (1966) Stratigraphy of the Chosen Group in Korea and South Manchuria and its relation to the Cambro-Ordovician formations of other areas, Section A, The Chosen Group of South Korea. Journal of the Faculty Science (University of Tokyo), Section II, v.16, p.1-84.

Park, C., Kim, N., Choi, S.-J. and Song, Y. (2020) Mg-phengite in carbonate rock syngenetically formed from hydrothermal fluid: Micro-textural evidence and mineral chemistry. Minerals, v.10, p.668. doi: 10.3390/min10080668.

Son, C.M. and Cheong, J.K. (1976) On the geologic structure of Pyeongchang area. Jour. Nat. Acad. Sci. R.O.K., Nat. Sci. Ser., v.16, p.221-245. 